\title{
Extracranial guiding structures for navigation to specific topographical sectors of the equine neopallium: an anatomical investigation performing three-dimensional distance measurements in adult warm-blooded horses
}

\author{
F. Heun' ${ }^{1}$, L. Böing ${ }^{1}$, J. Theunert ${ }^{2}$, H. Gasse ${ }^{1}$ \\ 'Institute of Anatomy, University of Veterinary Medicine Hannover, Hannover, Germany \\ 2Faculty II - Mechanical Engineering and Bio Process Engineering, University of Applied Sciences and Arts, \\ Hannover, Germany
}

[Received: 5 March 2021; Accepted: 29 April 2021; Early publication date: 17 May 2021]

\begin{abstract}
Background: This basically anatomical study focuses on two items; firstly, the establishment of a system for the cartographic subdivision of the neopallium; secondly, the topographical correlation of extracranial landmarks and intracranial sites on the neopallium.

Materials and methods: The surface of the neopallium was subdivided into 15 sectors with reference to a newly introduced pattern of Primary Sulci. The topographical link between extracranial landmarks and certain intracranial sites (i.e. neopallium sectors) was elaborated by using a simple stereotactic device and a computer-assisted measurement device. Measurements were performed between points on the head's outer surface and on the isolated brain.

Results and Conclusions: The introduction of an anatomical three-dimensional coordinate system was an essential key issue for this investigation. This setting facilitated the measurements and calculations of the so-called indirect distances that were characterised by their alignment along the three orthogonal axes $(x, y, z)$ of the anatomical coordinate system. The inter-individual comparison (16 adult horses [Equus caballus]) of the indirect distances revealed that each sector centre lay within a distinct morphometric residence area. The measured and calculated data also showed that each sector centre could be assigned to its proper extracranial landmark that - in comparison with other landmarks - was best suited for the optimal allocation of the sector centre point. (Folia Morphol 2022; 81, 2: 324-335)
\end{abstract}

Key words: brain cartography, encephalometry, craniometry, landmark

\section{INTRODUCTION}

The equine telencephalon recently attracted major scientific attention in veterinary medicine [16, 24, 34]; however, stereotactic manoeuvres were performed in dogs [30], but not in horses (Equus caballus). Ac- cordingly, our morphometric study was designed to elucidate the topographical relations between extracranial landmarks and intracranial sites on the neopallium. Previously, the applicability and usefulness of such extra-intra measurements and calculations

Address for correspondence: Dr. F. Heun, Institute of Anatomy, University of Veterinary Medicine Hannover, Bischofsholer Damm 15, D-30173 Hannover, Germany, e-mail: frederik.heun@tiho-hannover.de

This article is available in open access under Creative Common Attribution-Non-Commercial-No Derivatives 4.0 International (CC BY-NC-ND 4.0) license, allowing to download articles and share them with others as long as they credit the authors and the publisher, but without permission to change them in any way or use them commercially. 
were demonstrated in the field of equine craniometry [7] with special emphasis on the so-called indirect distances in a three-dimensional coordinate system.

Data from numerous equine craniometric studies $[7,10,18,19,22,25,26]$, various imaging procedures $[2,12,16,32,33]$ and some electrophysiological approaches $[1,3,6]$ are currently available. However, they appear limited in their methodical scope because a topographical link is missing between the two subjects of interest, i.e. skull (head surface) and brain. Kramer et al. [20] used extracranial landmarks for a surgical approach to the brain; Wijnberg et al. [35] used extracranial landmarks for the placement of electrodes for electroencephalography, but a comprehensive cartographic guideline is still not available.

This may, in part, be due to the lack of a uniform reference system for the horse's head, and - in particular - to the very complex and heterogeneous surface architecture of the equine neopallium $[4,9$, 24]. The recently elaborated cartographic pattern subdividing the surface of the equine neopallium $[5,13]$ was applied in this study as a promising tool to combine both, landmarks on the head and distinct sites on the brain's surface, for a comprehensive description of the topographical extra-intra relations. In order to allow the unanimous identification of the sulci (i.e. their courses and depths; cartographic pattern) the isolation of the brain from the cranial cavity was assumed to be indispensable at the present early state of this pilot study.

\section{MATERIALS AND METHODS}

\section{Specimens}

The heads of 16 adult warm-blooded horses were fixed by perfusion with $10 \%$ formalin via the left A. carotis communis shortly after euthanasia. The horses had been euthanized by medical staff at the Clinic for Horses (University of Veterinary Medicine Hannover, Hannover, Germany) to be used in the dissection courses of the Institute of Anatomy at the same university. No animals were exclusively euthanized for this study. All related procedures were carried out in accordance with the German Federal Law, i.e. the Protection of Animals Act (Tierschutzgesetz $\S 4$, $\S 7, \S 7 a)$ as well as the Directive of the European Parliament and of the Council for the Protection of Animals Used for Experimental and other Scientific Purposes (2010/63/EU). The project was reported to and approved by the Animal Welfare Officer of the University of Veterinary Medicine Hannover, Hannover, Germany (TVO-2018-V-70 of 4 September 2018).

\section{Settings}

The heads were frozen and longitudinally cut 15 $\mathrm{mm}$ to the right side of the median plane (to avoid damage to the left hemisphere). Then, the left half was placed on the stereotactic apparatus (the section plane lying on a specimen table). A simple stereotactic apparatus was built as previously described in detail [13]. Briefly, the specimen table was flexibly connected with a fixed base plate; hence, it could be lifted and adjusted to standardized angles ( 0 and 90 degrees). It also had scaled guide bars ( $\mathrm{mm}$ units) on its sides and, therefore, could be shifted precisely back and forth and side to side. Additionally, a drill machine was mounted in a stable vertical position above the specimen table (wood drill bit with a diameter of $3 \mathrm{~mm}$ ).

To ensure a uniform positioning of the different heads on the specimen table, the establishing of a uniform extracranial reference line (like for example the Frankfurt line in human medicine) was indispensable. Hence, the Hannover line was established: This ran along the crista facialis and extended to the head's caudal end. Accordingly, the head was placed in such a way that the Hannover line was always parallel to the longitudinal margin of the specimen table.

A three-dimensional anatomical coordinate system (Fig. 1) was established by using three extracranial reference planes, i.e. firstly, the horizontal plane called Hannover plane (at the level of the Hannover line); secondly, the transverse plane cutting the foramen supraorbitale; thirdly, the median plane. These planes were orthogonal, and all met in the so-called zero point of the head (ZP) and represented the three spatial axes: $x, y$ and $z$ (Fig. 1).

This setting allowed drilling at different angles (i.e. 90 degrees in the lateral view and 0 degrees in the dorsal view) and at different sites, i.e. at the so-called drilling points (D). The drilling points were topographically related to palpable anatomical landmarks, i.e. foramen supraorbitale, crista facialis, arcus zygomaticus, margo orbitalis, median plane. Three drilling points were placed parallel to the Hannover line, three parallel to the median plane (Fig. 2). This stereotactic drilling at the selected extracranial drilling points $(D)$ yielded intracranial target points $(T)$ at the internal surface of the calvaria and on the brain.

On the carefully removed brain, the facies convexa of the neopallium was subdivided into 15 sectors 


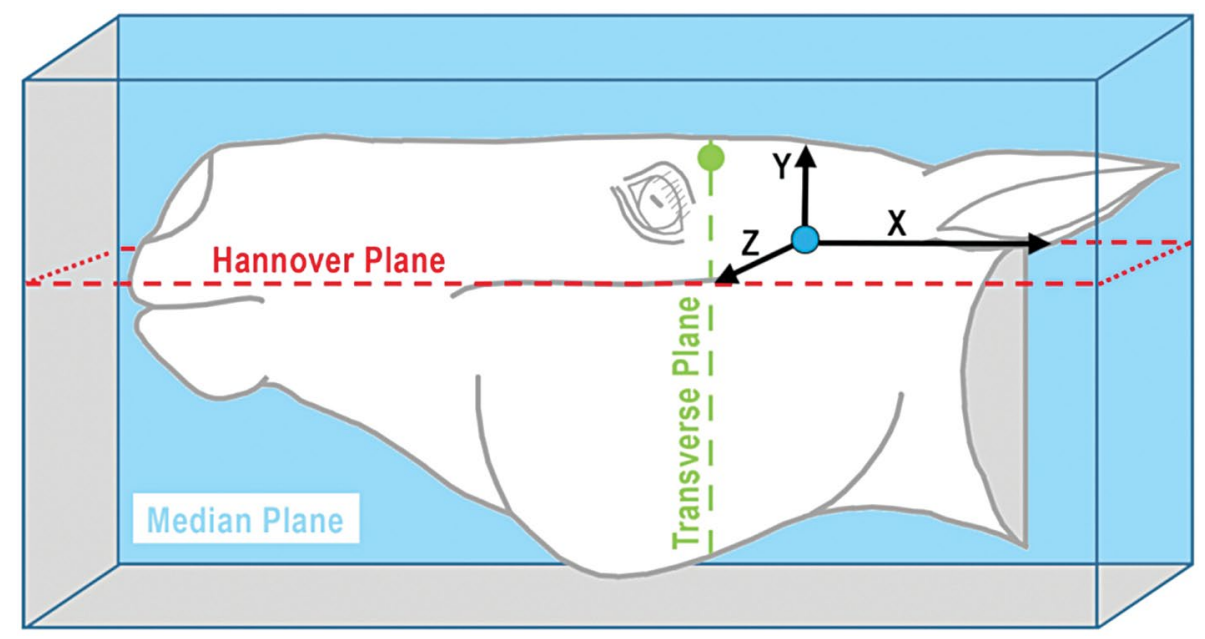

Figure 1. Graphical representation of the left half of an equine head. The horizontal Hannover plane (red dashed line) follows the crista facialis. The transverse plane (green dashed line) cuts the foramen supraorbitale (green dot); both are orthogonal to the third plane that is the median plane. In the median plane, all the three planes meet in the zero point of the head (blue dot). The arrows indicate the directions of the three spatial axes $(x, y, z)$ of the anatomical coordinate system.

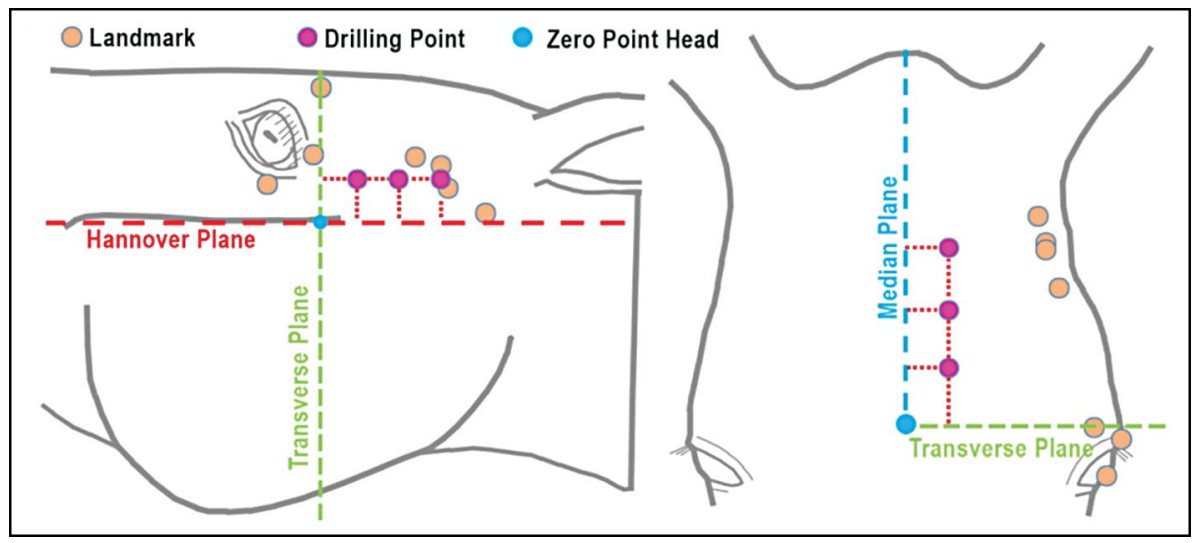

Figure 2. Sketch of an equine head in lateral and dorsal view. The three reference planes, i.e. Hannover plane (red), transverse plane (green) and median plane (blue), meet in the zero point of the head (blue point). The landmarks are osseous points which are easy to identify, and the drilling points are deduced from these landmarks. The red dotted lines mark the uniform distances between the respective drilling points and the reference planes.

(Fig. 3), as previously described [5, 13]. The sectors were delineated by the primary sulci and by auxiliary lines topographically related to the primary sulci. The centre of each sector was designated as the sector centre point (SCP). Additionally, the rostral pole (RP) and the caudal pole (CP) of the neopallium were marked (Fig. 3).

\section{Measurements and calculations}

Measurements were performed on the outside of the head (craniometry) and - after brain removal from the cranial cavity - on the surface of the isolated brain (encephalometry) using the scales of the moveable specimen table of the stereotactic apparatus that was shifted in either the longitudinal or transversal direction. Measurements on the macerated skulls (craniometry) were performed by using the Faro ${ }^{\circledR}$ Fusion measurement device (Faro Europe, Stuttgart, GER) together with the operating software DELCAM PowerINSPECT (DELCAM, Birmingham, UK) as previously described $[7,22,26]$.

The measured distances (Table 1) - designated as indirect distances - were strictly aligned parallel to the $x-, y$ - and $z$-axes of the head/skull/brain in accordance with the anatomical coordinate system (Fig. 1). On the isolated brain, the longitudinal 


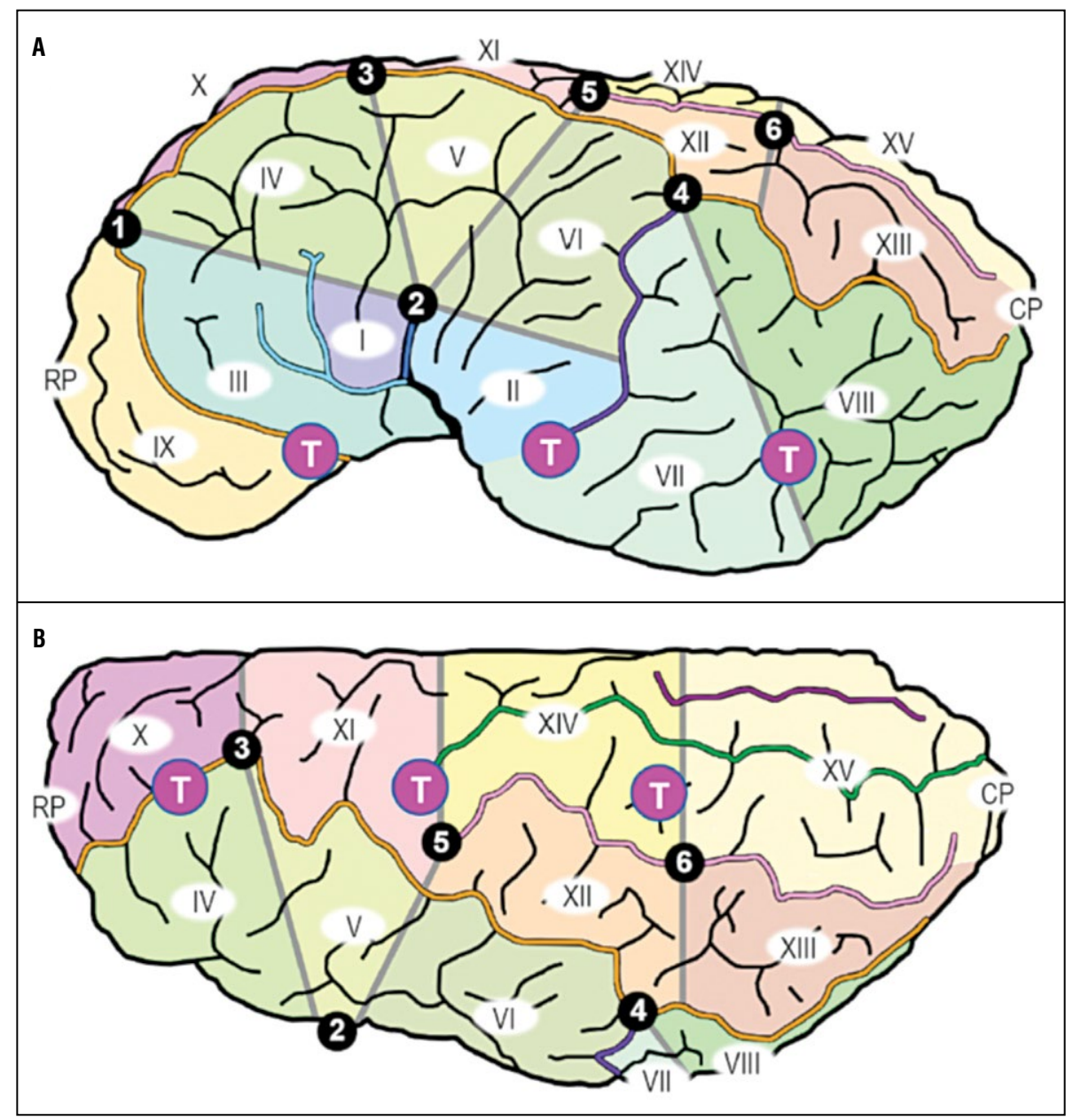

Figure 3. Graphical representation of 15 sectors (I-XV) of the equine neopallium. A. Lateral view $\left(90^{\circ}\right.$ angle); B. Dorsal view $\left(0^{\circ}\right.$ angle). The numbering of the sectors starts rostral and caudal to the fissura sylvia (sectors I and II) and then continues in a bow-like order in topographical relation to the primary sulci. The sectors are delineated by the primary sulci (colour-coded in accordance with Lang et al. [24]) and by auxiliary lines (grey). The auxiliary lines are related to standard orientation points (1-6, black) defined as follows: (1) the rostral point on the sulcus presylvius/sulcus coronalis; (2) the dorsal end of the fissura sylvia; (3) the most medial point on the sulcus coronalis/sulcus suprasylvius; (4) the intersection of the sulcus suprasylvius and the sulcus obliquus; (5) the rostral end of the sulcus ectomarginalis; (6) the point on the sulcus ectomarginalis halfway between point (5) and the caudal pole of neopallium. The rostral pole (RP) and caudal pole (CP) of the neopallium and the target points (T) are also marked. Colour-coding of each sulcus (S.): orange - S. presylvius/S. coronalis/S. suprasylvius; dark blue - F. sylvia; light blue $-\mathrm{S}$. diagonalis; purple - S. obliquus; pink - S. ectomarginalis; green $-\mathrm{S}$. marginalis; red $-\mathrm{S}$. endomarginalis.

Table 1. Compilation of measured indirect distances between points of interest on the outside of the head and skull (craniometry), of measured indirect distances between points on the surface of the isolated brain (encephalometry) and of calculated distances between extra- and intracranial points

\begin{tabular}{|c|c|c|}
\hline $\begin{array}{l}\text { Measurements on head } \\
\text { and macerated skull }\end{array}$ & $\begin{array}{c}\text { Measurements } \\
\text { on isolated neopallium }\end{array}$ & $\begin{array}{c}\text { Calculations } \\
\text { of extra-intra distances }\end{array}$ \\
\hline From - To & From - To & From - To \\
\hline$L-D$ & $\mathrm{~T}-\mathrm{SCP}$ & $\mathrm{L}-\mathrm{SCP}$ \\
\hline$Z P-L$ & $\mathrm{~T}-\mathrm{RP}$ & $\mathrm{ZP}-\mathrm{SCP}$ \\
\hline \multirow[t]{2}{*}{$Z P-D$} & $\mathrm{~T}-\mathrm{CP}$ & $\mathrm{ZP}-\mathrm{CP}$ \\
\hline & & $\mathrm{ZP}-\mathrm{RP}$ \\
\hline
\end{tabular}

$\mathrm{L}$ — landmark on head/skull; D — drilling point on head/skull; $\mathrm{T}$ — target point on brain; ZP — zero point of head; SCP — sector centre point on neopallium; RP — rostral pole of neopallium; $\mathrm{CP}$ - caudal pole of neopallium 


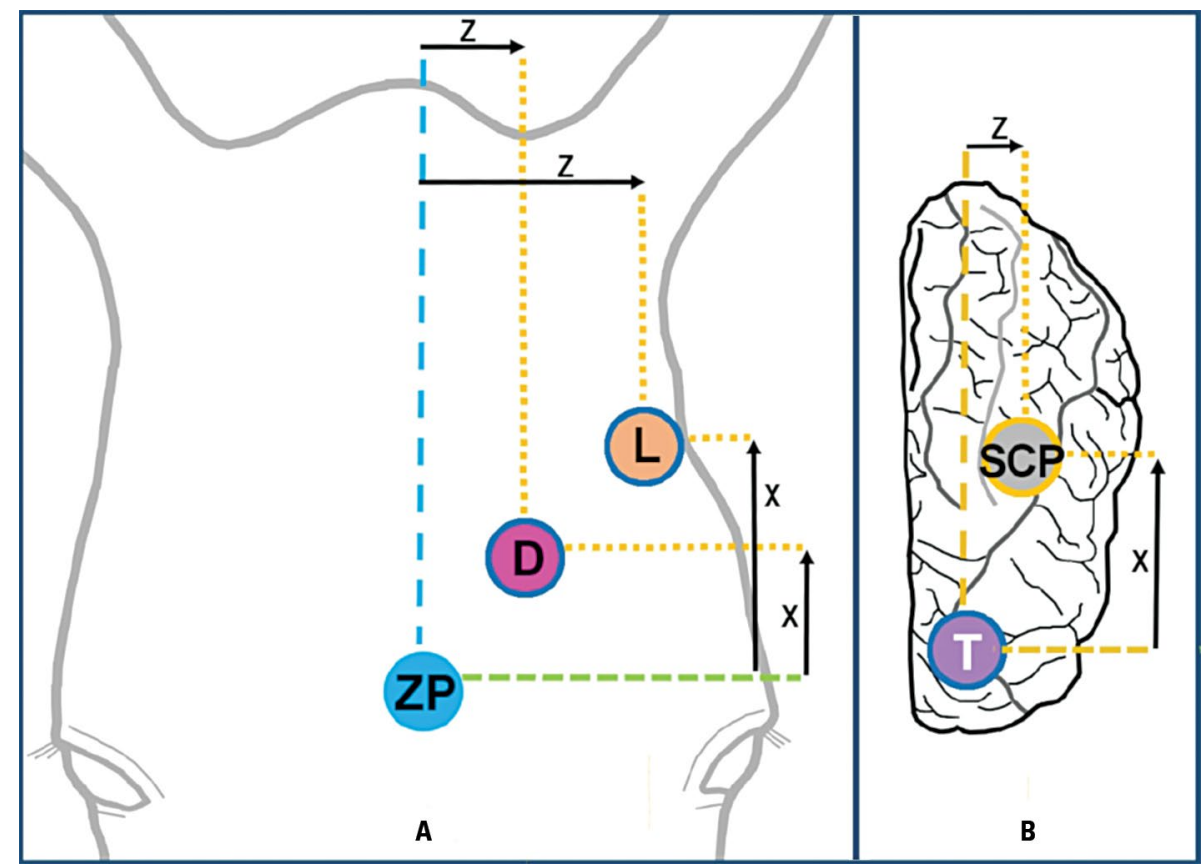

Figure 4. Graphical representation of the measurement of indirect distances in dorsal view; $\mathbf{A}$. Extracranial measurement between the zero point head (ZP) and an extracranial landmark (L) or a drilling point (D); B. Measurement between a target point (T) and a sector centre point (SCP) on the neopallium of the isolated brain. The indirect distances indicate how far away one point is from another in the caudal direction ( $x$-axis) or in the lateral direction ( $z$-axis). The direction of each indirect distance is aligned with the axes of the coordinate system. A direct distance (not shown here) would indicate the shortest, i.e. direct way between two points and, hence, would run obliquely in most cases.

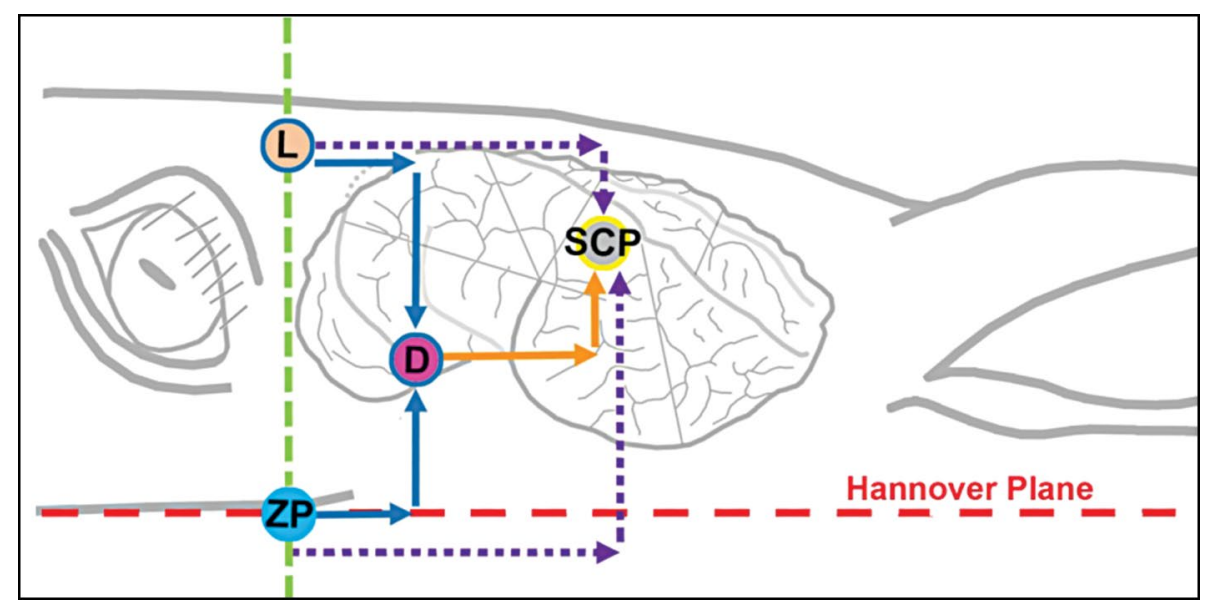

Figure 5. Graphical representation of the three steps for determining the extra-intra distances between extracranial points on the head/skull and intracranial sector centre points (SCP) on the brain; lateral view. Even though the encephalometry was performed on the isolated brain, the head and the brain were mounted together in this sketch to better visualise the entire procedure. Step 1: The two reference planes (Hannover plane [red] and transverse plane [green]) mark the position of the zero point head (ZP). Starting there (or at a landmark [L]), the indirect distance to the drilling point (D) was measured extracranially (blue arrows). Step 2: The indirect distance to a selected SCP was measured on the isolated brain, starting from the target point ( $T$; identical with $\mathrm{D}$ in this lateral view) on the brain (orange arrows). Step 3: The distance between the extracranial L or ZP and the SCP on the neopallium was calculated (purple arrows).

axis was recognized by the target points that lay on a line parallel to the Hannover line and median plane of the head/skull, respectively; the zero point was an essential reference point (Fig. 4).

Determining the indirect distances between extracranial landmarks or the zero point head (ZP) and sites on the brain (SCPs) - "extra-intra distances" - was performed in three steps:

- Step 1 (craniometry): the indirect distance between an extracranial landmark (or the ZP) and an extracranial drilling point was measured on the skull (Fig. 5, blue arrows); 
- Step 2 (encephalometry): the indirect distance between a target point on the neopallium and a selected SCP was measured on the isolated brain (Fig. 5, yellow arrows);

- Step 3 (calculation): the indirect distance between the extracranial landmark (or the ZP) and the SCP was calculated by means of simple arithmetic addition or subtraction, depending on the topographical relation (Fig. 5, purple dotted arrows). Finally, for the metric and arithmetic data of all 16 horses (Table 2), the mean values, the standard deviations and the differences between the longest and shortest indirect distances were calculated using Microsoft ${ }^{\circledR}$ Excel $^{\circledR} 2016$ (Microsoft Corporation, Redmond, WA, USA). Diagrams displaying the positions of the SCP in the coordinate system were generated with Microsoft Excel and subsequently graphically supplemented (Adobe Photoshop CS6 Extended 13.0.1; Adobe Systems, San Jose, CA, USA) to highlight distinct sites (Fig. 6).

\section{RESULTS}

All SCP were always located dorsal and caudal to the zero point head (ZP), i.e. caudal to the foramen supraorbitale and dorsal to the Hannover plane. The rostral pole of the neopallium lay on average on the same transverse plane as the ZP. In the inter-individual comparison, the topographical relations between the SCPs of the neopallium and the ZP varied. However, a common basic pattern of localisation was obvious, meaning that each of the 15 SCPs (I-XV) - if compared in the 16 horses - had its position within a certain limited residence area (Fig. 6; see colour-coded areas).

These topographical relations between the SCPS of the neopallium and the ZP were visualised by using the mean values of the respective indirect distances mentioned above and by projecting their mean localisations onto the surface of the head (Figs. 7, 8). This allowed identifying the so-called mean localisation of each SCP with reference to the three reference planes.

The values of the indirect distances between extracranial landmarks and SCPs on the neopallium showed inter-individually variable characteristics, depending on the spatial axis and the selected landmark. Certain landmarks and the indirect distances related to them showed the least inter-individual differences, depending on the spatial axis (Table 2) and on the selected SCP. Such landmarks, one for each SCP in the respective spatial axis, are recommended as the guiding structure to the respective SCP. With reference to these guiding structures, each SCP could be located in an area smaller than $23 \mathrm{~mm}$ in diameter. The calculated indirect distances between landmarks and the SCPs other than those listed in Table 2 showed more inter-individual differences; these data (not listed here) are available on request.

Considering the longitudinal axis (Table 2), one landmark, i.e. the most dorsal and caudal point on the arcus zygomaticus, is particularly recommended to be used as the most suitable guiding structure to SCP I and all subsequent caudal SCPs. As for SCPs located further rostrally, other landmarks (Table 2) are recommended because the indirect distances starting from these landmarks showed smaller inter-individual differences. In the vertical axis (Table 2), the porus acusticus externus is particularly recommended for most of the ventral, dorsal and laterocaudal SCPs because the indirect distances related to these showed the least inter-individual differences. In contrast, the most ventral point on the margo orbitalis is recommended as the guiding structure for lateral SCPs (Table 2). The median plane was a suitable guiding structure for the indirect distances in the transversal direction (z-axis; Table 2). However, the foramen supraorbitale is also recommended, e.g. as the guiding structure to the SCPs near the fissura sylvia (Table 2).

\section{DISCUSSION}

Measurements and calculations of distances between extracranial landmarks and specific sites on the brain require appropriate anatomical reference systems in combination with an adequate stereotactic device to facilitate, firstly, the standardized and reproducible placement and probing/drilling on the head and, secondly, the reproducible placement of the isolated brain for the purpose of measurements on the neopallium.

The stereotactic apparatus used in this study differed from those that had been applied previously on pigs [27], cattle [21] or dogs [17, 30]. In those settings, a frame was attached to the intact head and the drill bit or probe was movably attached to it. Our setting was simpler and yet effective because it overcame the initial challenge in terms of uniform specimen positioning by using heads cut in the paramedian plane. This had several advantages. Firstly, it allowed removal of the brain (for separate measurements); secondly, it allowed adjusting of the median plane of the stereotactic system (i.e. the 
Table 2. Compilation of selected indirect distances between an extracranial landmark and a sector centre point (SCP, I-XV) of the neopallium or the rostral/caudal pole of the neopallium ( $R P, C P)$ in a longitudinal (x-axis), vertical (y-axis) and transverse (z-axis) direction. Considering each SCP, the indirect distance that showed the least differences in the inter-individual comparison of the 16 horses is listed. The difference between the maximum and minimum value of the indirect distance represents the diameter of the morphometric residence area of the respective SCP. A negative sign indicates that the SCP lies rostral (x-axis), ventral (y-axis) or medial (z-axis) of the extracranial landmark

\begin{tabular}{|c|c|c|c|c|}
\hline Extracranial landmark & SCP & $\mathbf{M}[\mathrm{mm}]$ & SD [mm] & Max-Min [mm] \\
\hline \multicolumn{5}{|c|}{ Indirect distances along the longitudinal axis (x-axis) } \\
\hline Caudodorsal point on arcus zygomaticus & I & -47 & 5 & 14 \\
\hline Caudodorsal point on arcus zygomaticus & $\|$ & -29 & 5 & 16 \\
\hline Porus acusticus externus & III & -75 & 4 & 13 \\
\hline Most rostral point on margo orbitalis & IV & 95 & 5 & 15 \\
\hline Caudodorsal point on arcus zygomaticus & V & -32 & 4 & 15 \\
\hline Caudodorsal point on arcus zygomaticus & $\mathrm{VI}$ & -18 & 5 & 15 \\
\hline Caudodorsal point on arcus zygomaticus & VII & -11 & 5 & 18 \\
\hline Caudodorsal point on arcus zygomaticus & VIII & 9 & 6 & 19 \\
\hline Most rostral point on margo orbitalis & IX & 80 & 4 & 14 \\
\hline Most ventral point on margo orbitalis & $X$ & 47 & 6 & 22 \\
\hline Porus acusticus externus & $\mathrm{XI}$ & -38 & 5 & 14 \\
\hline Caudodorsal point on arcus zygomaticus & XII & -3 & 5 & 16 \\
\hline Caudodorsal point on arcus zygomaticus & XIII & 17 & 4 & 15 \\
\hline Caudodorsal point on arcus zygomaticus & XIV & 1 & 5 & 18 \\
\hline Caudodorsal point on arcus zygomaticus & $X V$ & 23 & 4 & 14 \\
\hline Porus acusticus externus & $\mathrm{RP}$ & -102 & 5 & 18 \\
\hline Caudodorsal point on arcus zygomaticus & $\mathrm{CP}$ & 35 & 4 & 13 \\
\hline \multicolumn{5}{|c|}{ Indirect distances along the vertical axis (y-axis) } \\
\hline Most ventral point on margo orbitalis & 1 & 25 & 6 & 17 \\
\hline Porus acusticus externus & $\|$ & 30 & 5 & 15 \\
\hline Foramen supraorbitale & III & -43 & 6 & 18 \\
\hline Most ventral point on margo orbitalis & IV & 51 & 6 & 18 \\
\hline Porus acusticus externus & V & 63 & 5 & 17 \\
\hline Porus acusticus externus & $\mathrm{Vl}$ & 49 & 4 & 17 \\
\hline Most ventral point on margo orbitalis & VII & 9 & 6 & 18 \\
\hline Porus acusticus externus & VIII & 24 & 5 & 21 \\
\hline Most ventral point on margo orbitalis & IX & 13 & 7 & 22 \\
\hline Foramen supraorbitale & $X$ & -10 & 5 & 15 \\
\hline Porus acusticus externus & $X I$ & 73 & 4 & 14 \\
\hline Porus acusticus externus & XII & 58 & 6 & 22 \\
\hline Most caudal point on arcus zygomaticus & XIII & 11 & 6 & 22 \\
\hline Porus acusticus externus & XIV & 65 & 5 & 18 \\
\hline Porus acusticus externus & $X V$ & 53 & 5 & 16 \\
\hline Porus acusticus externus & $\mathrm{RP}$ & 38 & 5 & 13 \\
\hline Porus acusticus externus & $\mathrm{CP}$ & 36 & 4 & 14 \\
\hline \multicolumn{5}{|c|}{ Indirect distances along the transverse axis (z-axis) } \\
\hline Foramen supraorbitale & 1 & -33 & 4 & 12 \\
\hline Foramen supraorbitale & $\|$ & -27 & 5 & 14 \\
\hline Median plane & III & 40 & 6 & 18 \\
\hline Most dorsal point on arcus zygomaticus & IV & -50 & 4 & 13 \\
\hline
\end{tabular}


Table 2 (cont.). Compilation of selected indirect distances between an extracranial landmark and a sector centre point (SCP, I-XV) of the neopallium or the rostral/caudal pole of the neopallium (RP, CP) in a longitudinal (x-axis), vertical (y-axis) and transverse (z-axis) direction. Considering each SCP, the indirect distance that showed the least differences in the inter-individual comparison of the 16 horses is listed. The difference between the maximum and minimum value of the indirect distance represents the diameter of the morphometric residence area of the respective SCP. A negative sign indicates that the SCP lies rostral (x-axis), ventral (y-axis) or medial (z-axis) of the extracranial landmark

\begin{tabular}{lcccc}
\hline Extracranial landmark & SCP & M [mm] & SD [mm] & Max-Min [mm] \\
\hline Foramen supraorbitale & V & -41 & 4 & 11 \\
Caudodorsal point on arcus zygomaticus & VI & -30 & 4 & 14 \\
Median plane & VII & 56 & 4 & 14 \\
Median plane & VIII & 49 & 4 & 14 \\
Median plane & IX & 34 & 3 & 12 \\
Median plane & X & 13 & 3 & 13 \\
Median plane & XI & 17 & 3 & 12 \\
Median plane & XII & 36 & 4 & 14 \\
Median plane & XIII & 40 & 3 & 11 \\
Median plane & XIV & 17 & 4 & 14 \\
Caudodorsal point on arcus zygomaticus & XV & -60 & 4 & 13 \\
Median plane & RP & 18 & 4 & 14 \\
Caudodorsal point on arcus zygomaticus & $\mathrm{CP}$ & -62 & 5 & 15 \\
\hline
\end{tabular}

$\mathrm{N}=16 ; \mathrm{M}$ - mean; SD — standard deviation; Max-Min — difference between longest and shortest indirect distance

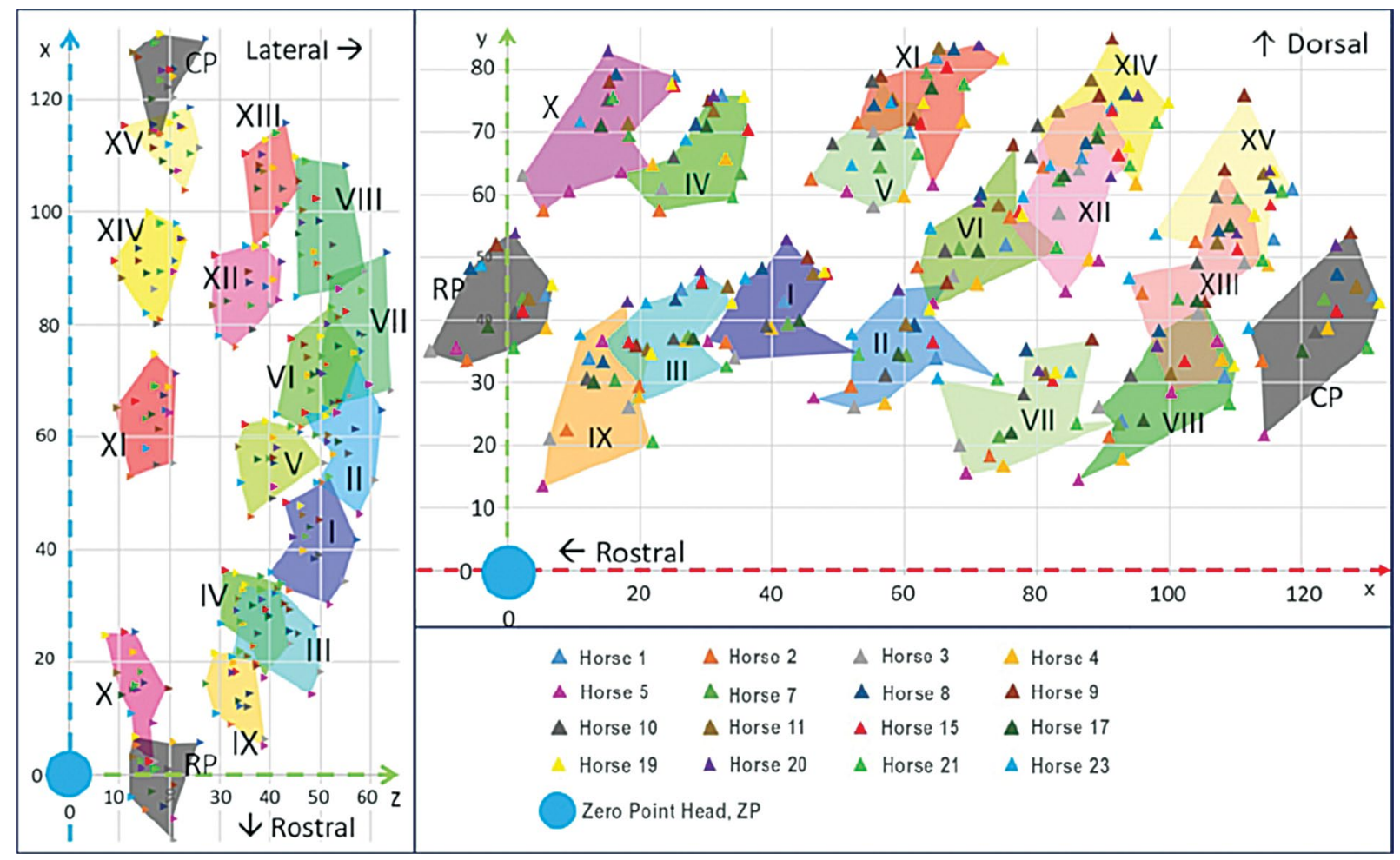

Figure 6. Localisation of the sector centre points (SCP) of the neopallium of 16 horses in a synoptic graphical representation to display their topographical relations to the zero point head (ZP, blue dot) in a lateral view and dorsal view (scale: $\mathrm{mm}$ ). The Hannover plane (red, dashed line) the transverse plane (green, dashed) and the median plane (blue, dashed) correspond with the axes of the anatomical coordinate system and they meet in the ZP; the ZP of all 16 horses are superimposed to establish a uniform reference point in this synopsis. Starting from this point, the SCPs (I-XV) and the rostral pole (RP) and caudal pole (CP) were then positioned to scale according to their indirect distances (the diagram was created with MS Excel and modified with Adobe Photoshop). The outlines of the coloured fields express the positional variations in the SCPs (coloured triangles) in the inter-individual comparison of the 16 horses (residence areas). 


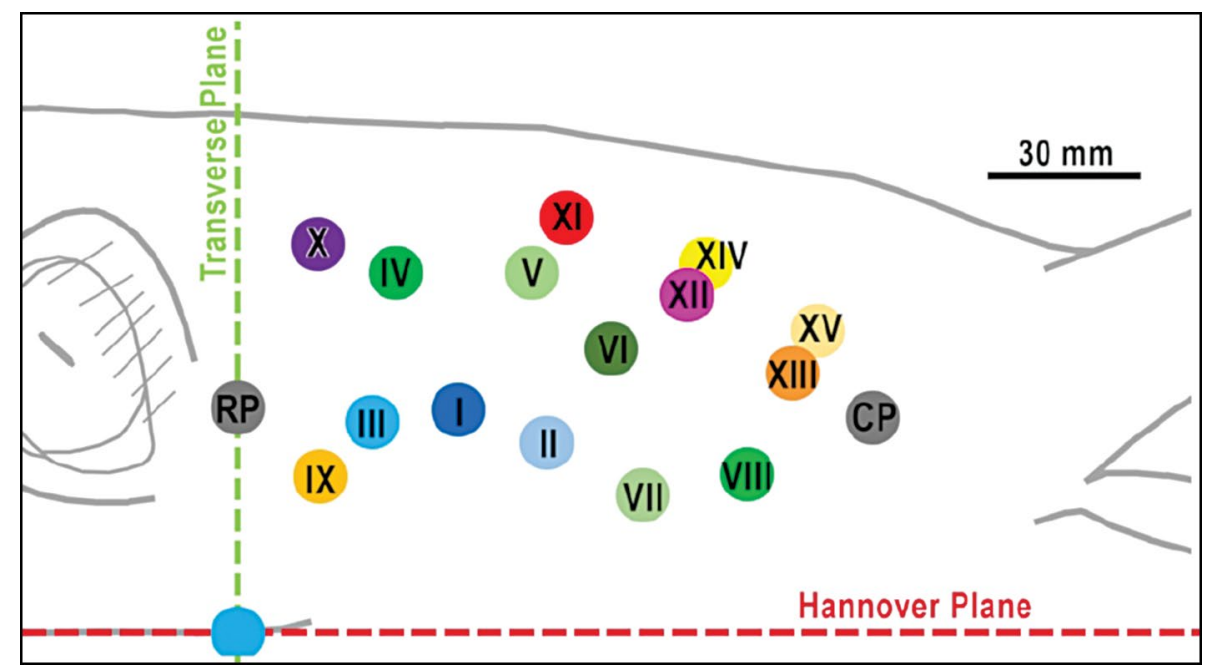

Figure 7. Graphical projection of the mean localisations of the sector centre points (SCPs, I-XV) of the left neopallium onto the head surface in a lateral view. Two of the three standard reference planes (Hannover plane [red] and transverse plane [green]) and the zero point head (blue dot) were used as reference points for the projection onto the head surface. Using the positions of the individual SCPs of all 16 horses, the mean localisation of each SCP was calculated and projected onto the head surface and drawn to scale; RP — rostral pole; CP — caudal pole of the neopallium.

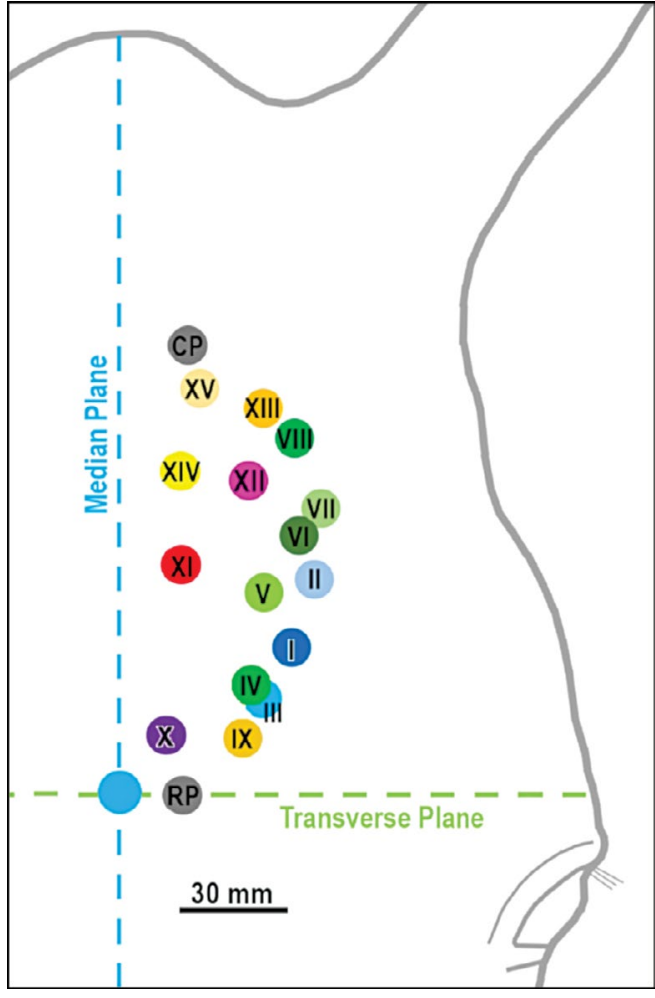

Figure 8. Graphical projection of the mean localisations of the sector centre points (SCPs, I-XV) of the left neopallium onto the head surface in a dorsal view. Two of the three standard reference planes (median plane [blue] and transverse plane [green]) and the zero point head (blue dot) were used as reference points for the projection onto the head surface. Using the positions of the individual SCPs of all 16 horses, the mean localisation of each SCP was calculated and projected onto the head surface and drawn to scale; $\mathrm{RP}$ - rostral pole; $\mathrm{CP}$ - caudal pole of the neopallium. specimen table) with the paramedian plane of the specimen (i.e. the cutting surface of the head and brain); thirdly, it allowed adjusting the specimens along the table's scaled margins that represented the $x$-axis and $y$-axis of the stereotactic and anatomical coordinate system. Head and brain, though separated from each other, bore identical marks (i.e. external drilling points and target points on the neopallium), which were identically aligned along the Hannover plane and the median plane [13], i.e. two of the three reference planes.

The three established orthogonal planes formed the basis for the three-dimensional-navigation, for the measurements of the horse's head and brain, and for the distance calculations. In human medicine, similar patient-related coordinate systems and reference planes (like the Frankfurt plane) are commonly used in imaging or surgery $[14,29]$.

Previous systems for orientation appeared less suitable for this study because they referred to two planes only instead of three [31] or were only used for the examination of the brain [16], i.e. without reference to extracranial landmarks.

The zero point of the head (ZP) within our anatomical coordinate system was a valuable morphometric feature as it could be easily projected onto the surface of the head in the lateral and in the dorsal view. Previously, such central reference points had been used in equine craniometry [11]; however, 
to calculate virtually instead of physically palpable points and - as such — were not suitable to serve as anatomical guiding structure. The position of the ZP was deduced from the combination of the three designated orthogonal standard planes and, hence, could be regarded as a proportional parameter that partially adjusted imbalances related to individual variations in size and shape of the head and brain.

The distinct, appropriately narrow allocation and designation of sites on the neopallium was challenged by the complex gyration pattern, which is known to be extremely heterogeneous in the equine brain $[9,23,24]$. The subdivision of the facies convexa into 15 sectors, in accordance with the recently introduced cartographic mapping system $[5,13]$, was the key element for the objective and reproducible orientation on the neopallium. Hence, the use of isolated brain specimens for the unanimous determination of these sectors was regarded as an indispensable technical prerequisite; this method was preferred instead of computer tomography and/or magnetic resonance imaging at this initial state of our study. Such imaging procedures are of course in the scope of future investigations now that the basic topographic extra-intra relations (skull vs. brain) and the neopallium's cartographic pattern (sectors) have been principally elucidated.

The morphometric procedure applied here highlighted the topography of the equine brain in situ because, for the first time, extracranial landmarks were topographically linked to selected cerebral surface structures in horses (extra-intra calculations/measurements). The immanent biological variability of both, skull and neopallium [24], commonly influences the results of any morphometric procedure. To exclude growth-related differences, only adult horses ( $>5$ years) were used in this study, bearing in mind that age-related differences in equine skulls have not been detected in horses older than 5 years [7]. In terms of this, our pool of specimens (adult, warm-blooded horses) was homogeneous.

Considering that morphometric data of two biologically variable systems (skull and neopallium) were linked in this study, one could not expect to find a certain SCP in the precisely identical spot in different horses. Yet, the comparison of data revealed that each SCP was localised in a limited space, i.e. the residence area. This finding is in line with general morphometric principles that apply in a three-dimensional system $[7,26]$. Consequently, the residence area is regarded as a valuable descriptive tool of allocation of the SCPs.
Several extracranial landmarks on the equine head had been recommended $[7,20,28,36]$ and were examined in this study. However, our data emphasized that one particular landmark is not equally suitable for all sites on the neopallium in general. Rather, the choice of a distinct, specific landmark (i.e. the guiding structure) is recommended for the most precise navigation to the requested target site (SCP): the lists of selected data of indirect distances presented here and in the much more comprehensive data set including direct distances [13] are also proposed to be used as manuals of reference, indicating the appropriate guiding structure for accurate manoeuvres to an SCP.

The cartographic system of sectors $[5,13]$ is emphasized as a useful supplementary means for the distinct descriptive allocation of investigated sites in the case that certain techniques like, e.g. previously performed diagnostic electroencephalographic procedures [36], imaging studies [16] or surgery [20] should be further developed and elaborated for the application in horses. For example, the area that was electrophysiologically $[3,6]$ or histologically $[8,15]$ identified as the motor cortex is very likely to be partially located in sector XI of the neopallium.

\section{CONCLUSIONS}

The elaborated map of standardised sectors on the neopallium was an effective tool to overcome the orientation problems caused by the heterogeneous surface architecture of the equine brain. The proposed sectors were adequately small enough to perform the distinct and unanimous allocation and designation of targeted sites on the brain. The coordinate system specifically elaborated for the equine head facilitated the topographical, metric linkage of extracranial, palpable landmarks and the neopallium's surface sectors. The choice of the appropriate landmarks on the head's outer surface enabled the reproducible navigation towards the different sectors. The presented anatomical data are supposed to represent a substantially sound basis for studies by means of diagnostic imaging systems like computed tomography or magnetic resonance imaging.

\section{Acknowledgements}

We would like to thank our native speaker, Mrs. Frances Sherwood-Brock, who most meticulously revised the English manuscript.

Conflict of interest: None declared 


\section{REFERENCES}

1. Adrian ED. The somatic receiving area in the brain of the shetland pony. Brain. 1946; 69(1): 1-8, doi: 10.1093/ brain/69.1.1.

2. Arencibia A, Vazquez JM, Ramirez JA, et al. Magnetic resonance imaging of the normal equine brain. Vet Radiol Ultrasound. 2001; 42(5): 405-409, doi: 10.1111/j.17408261.2001.tb00959.x, indexed in Pubmed: 11678560.

3. Arloing MS. Détermination des points excitables du manteau de I' héminsphère des animaux solipèdes. Application a la topographie cérébrale. Association française pour I'avancement des sciences. 1879; 7: 995-1001.

4. Böhme G. (ed.) Nickel R, Schummer A, Seiferle E. Lehrbuch der Anatomie der Haustiere, Band IV: Nervensystem, Sinnesorgane, endokrine Drüsen (4th ed.). Parey, Stuttgart, Germany 2004.

5. Böing L. Die arterielle Vaskularisation der Gehirnoberfläche beim adulten Warmblutpferd: Anatomische Untersuchung unter Berücksichtigung des tierartspezifischen Furchungsmusters des Neopalliums (doctoral dissertation). University of Veterinary Medicine, Hannover 2020. https:// elib.tiho-hannover.de/receive/tiho_mods_00001263.

6. Breazile JE, Swafford BC, Biles DR. Motor cortex of the horse. Am J Vet Res. 1966; 27(121): 1605-1609, indexed in Pubmed: 5971615.

7. Brucker P. Morphometrische Untersuchung des Hirnschädels vom Pferd mit einem computergestützten 3-dimensionalen Messsystem (doctoral dissertation). Cuvillier Verlag, Göttingen 2015. https://elib.tiho-hannover.de/ receive/etd_mods_00000427.

8. Cozzi B, De Giorgio A, Peruffo A, et al. The laminar organization of the motor cortex in monodactylous mammals: a comparative assessment based on horse, chimpanzee, and macaque. Brain Struct Funct. 2017; 222(6): 2743-2757, doi: 10.1007/s00429-017-1369-3, indexed in Pubmed: 28210850.

9. Dexler H. Beiträge zur Kenntniss des feineren Baues des Zentralnervensystems der Ungulaten. Gegenbaurs Morphologisches Jahrbuch. 1904; 32: 288-389.

10. Driesch A. vd. A guide to the measurement of animal bones from archaeological sites. Pea Mus Bull 1. Harvard University, Cambridge, Mass 1978.

11. Evander RL. Craniometry of the equidae part I: two-dimensional shape analysis. Paludicola. 2008; 7(1): 1-13.

12. Ferrell EA, Gavin PR, Tucker RL, et al. Magnetic resonance for evaluation of neurologic disease in 12 horses. Vet Radiol Ultrasound. 2002; 43(6): 510-516, doi: 10.1111/j.17408261.2002.tb01041.x, indexed in Pubmed: 12502103.

13. Heun F. Morphometrische Untersuchung der topographischen Beziehungen zwischen externen Landmarks am Kopf und kartographischen Mustern des Neopalliums bei adulten Warmblutpferden (doctoral dissertation). University of Veterinary Medicine, Hannover 2020. https://elib. tiho-hannover.de/receive/tiho_mods_00001268.

14. Hofmann E, Fimmers R, Schmid M, et al. Landmarks of the Frankfort horizontal plane : Reliability in a three-dimensional Cartesian coordinate system. J Orofac Orthop. 2016; 77(5): 373-383, doi: 10.1007/s00056-016-0045-1, indexed in Pubmed: 27502792.

15. Hummel G. Die Feinstruktur der motorischen GroBhirnrinde des Pferdes. Zbl Vet Med C. 1976; 5: 35-53.
16. Johnson PJ, Janvier V, Luh WM, et al. Equine stereotaxtic population average brain atlas with neuroanatomic correlation. Front Neuroanat. 2019; 13: 89, doi: 10.3389/ fnana.2019.00089, indexed in Pubmed: 31636547.

17. Kani Y, Cecere TE, Lahmers K, et al. Diagnostic accuracy of stereotactic brain biopsy for intracranial neoplasia in dogs: Comparison of biopsy, surgical resection, and necropsy specimens. J Vet Intern Med. 2019; 33(3): 1384-1391, doi: 10.1111/jvim. 15500, indexed in Pubmed: 30990928.

18. Komosa M, Moliński K, Godynicki S. The variability of cranial morphology in modern horses. Zoolog Sci. 2006; 23(3): 289-298, doi: 10.2108/zsj.23.289, indexed in Pubmed: 16603822 .

19. Krahmer R. Messungen am Kopfskelett des Pferdes. Ein Beitrag zur Bedeutung der Kraniologie (doctoral dissertation). Karl-Marx-University, Leipzig 1963.

20. Kramer J, Coates JR, Hoffman AG, et al. Preliminary anatomic investigation of three approaches to the equine cranium and brain for limited craniectomy procedures. Vet Surg. 2007; 36(5): 500-508, doi: 10.1111/j.1532950X.2007.00297.x, indexed in Pubmed: 17614932.

21. Kuhla B, Bellmann O, Metges CC. Technical note: An apparatus for catheterization of the lateral brain ventricle in Holstein cows. J Dairy Sci. 2010; 93(12): 5837-5841, doi: 10.3168/jds.2010-3431, indexed in Pubmed: 21094756.

22. Lang A, Brucker $P$, Ludwig $M$, et al. The challenge of extra-intra craniometry: a computer-assisted three-dimensional approach on the equine skull. Folia Morphol. 2017; 76(3): 458-472, doi: 10.5603/FM.a2016.0082, indexed in Pubmed: 28026847.

23. Lang A, Sherwood-Brock F, Gasse H. Hermann Dexler's "Beiträge zur Kenntnis des feineren Baues des Zentralnervensystems der Ungulaten." An annotated English translation of the original German article; Part V: Telencephalon - adult stages. Hannover 2018a. https://doi. org/10.15487/tiho.4_2018.1/5 (2018).

24. Lang A, Wirth G, Gasse H. Review of the surface architecture of the equine neopallium: Principle elements of a cartographic pattern of sulci revisited and further elaborated. Anat Histol Embryol. 2018; 47(4): 280-297, doi: 10.1111/ahe.12355, indexed in Pubmed: 29542168.

25. Löffler K. Untersuchungen über die Wachstumsverhältnisse der Kopfknochen des Pferdes (doctoral dissertation). Hessische Ludwigs-Universität, Giessen 1919.

26. Ludwig M. Computergestützte Craniometrie beim Pferd unter Berücksichtigung altersabhängiger Lageverschiebungen osteologischer Landmarks. (doctoral dissertation). Cuvillier Verlag, Göttingen 2015. https://elib.tiho-hannover.de/receive/etd_mods_00000406.

27. Marcilloux JCA. Stereotaxic apparatus for the study of the central nervous structures in the pig. Brain Res Bull. 1989; 22: 591-597, doi: 10.1016/0361-9230(89)90118-4.

28. Mysinger PW, Redding RW, Vaughan JT, et al. Electroencephalographic patterns of clinically normal, sedated, and tranquilized newborn foals and adult horses. Am J Vet Res. 1985; 46(1): 36-41, indexed in Pubmed: 3970440.

29. Park JAh, Lee JS, Koh KS, et al. Using the zygomatic arch as a reference line for clinical applications and anthropological studies. Surg Radiol Anat. 2019; 41(5): 501-505, doi: 10.1007/s00276-018-2162-6, indexed in Pubmed: 30552488. 
30. Rossmeisl JH, Andriani RT, Cecere TE, et al. Frame-based stereotactic biopsy of canine brain masses: technique and clinical results in 26 cases. Front Vet Sci. 2015; 2: 20, doi: 10.3389/fvets.2015.00020, indexed in Pubmed: 26664949.

31. Stoll M, Ros K, Vogt C, et al. The hemisphere model: a new description of directions for head radiographs in the horse. Pferdeheilkunde. 2011; 27(2): 115-118.

32. Stuckenschneider K. Magnetresonanztomographische Untersuchungen der Gehirnregion gesunder und neurologisch erkrankter Pferde mit einer Feldstärke von 3 Tesla. (doctoral dissertation). Cuvillier Verlag, Göttingen 2013. https://elib.tiho-hannover.de/receive/ etd_mods_00000668.

33. Stuckenschneider K, Hellige M, Feige K, et al. 3-Tesla magnetic resonance imaging of the equine brain in healthy horses - Potentials and limitations. Pferdeheilkunde. 2014; 30(6): 657-670, doi: 10.21836/Pem20140605.

34. van der Ree M, Wijnberg I. A review on epilepsy in the horse and the potential of Ambulatory EEG as a diagnostic tool. Vet Q. 2012; 32(3-4): 159-167, doi: 10.1080/016521 76.2012.744496, indexed in Pubmed: 23163553.

35. Wijnberg ID, van der Ree M, van Someren P. The applicability of ambulatory electroencephalography (AEEG) in healthy horses and horses with abnormal behaviour or clinical signs of epilepsy. Vet Q. 2013; 33(3): 121-131, doi: 10.1080/0 1652176.2013.842075, indexed in Pubmed: 24111950.

36. Williams DC, Aleman M, Holliday TA, et al. Qualitative and quantitative characteristics of the electroencephalogram in normal horses during spontaneous drowsiness and sleep. Vet Intern Med. 2008; 22(3): 630-638, doi: 10.1111/j.19391676.2008.0096.x, indexed in Pubmed: 18466241. 